\title{
Macrovascular Disease in the Elderly with Type 1 Diabetes
}

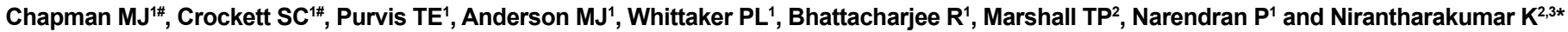

${ }^{1}$ School of Clinical and Experimental Medicine, University of Birmingham, UK

${ }^{2}$ School of Health and Population Sciences, University of Birmingham, UK

${ }^{3}$ Institute of Digital Healthcare, University of Warwick, UK

\begin{abstract}
Macrovascular disease (MVD) is a major complication of type 1 diabetes mellitus. However, accurate data on the prevalence and impact of macrovascular disease in the elderly with type 1 diabetes is lacking. This is despite life expectancy increasing in this population. Using data from over 400 general practices in the UK, the prevalence of macrovascular disease and factors associated with it were identified in elderly (over 65years) patients with type 1 diabetes for the year 2008. In this population, there was high prevalence of macrovascular disease(39.5\%). Patients with macrovascular disease were significantly older, had a longer duration of diabetes, a positive history of smoking and higher $\mathrm{HbA} 1 \mathrm{cvalues}$. Our analysis demonstrates a high burden of macrovascular disease in elderly patients with type 1 diabetes. We need to explore how best to address this disease in this population.
\end{abstract}

Keywords: Type 1 diabetes; Cardiovascular disease; Elderly

\section{Introduction}

Patients with type 1 diabetes have a high incidence of macrovascular disease (MVD) and therefore pose a challenge to healthcare in the UK [1]. For example, their risk of ischaemic heart disease is five times greater than in the normal population [2]. The combined effect of diabetes and macrovascular diseases results in an increased risk of death among this population [3]. Despite this, poor recording and management of cardiovascular risk factors exists in type 1 diabetes in the UK [4]. However, life expectancy of these patients has improved considerably over the past few decades due to better understanding of the illness and improved treatment options $[5,6]$.

Increased life expectancy means there are many elderly with type 1 diabetes who have specific care needs. In order to meet their care needs, an understanding of the occurrence of macrovascular diseases and factors associated with them is imperative. The aim of this crosssectional study is to determine the burden of macrovascular disease in elderly type 1 diabetes patients and identify key risk factors associated with macrovascular disease in this population.

\section{Materials and Methods}

\section{Ethical approval}

Approval was obtained from the scientific review committee of the Cegedim Strategic Data Medical Research Ltd, the provider of the database (Reference Number: 12-046R).

\section{Data and sample selection}

This study used baseline data from The Health Improvement Network (THIN) [7], a database of anonymised patient information entered by general practices using the Vision System [8]. THIN contains primary care records of over 7.5 million patients from over 400 general practices in the UK and is representative of the UK population [9]. THIN has been independently verified for use in pharmacoepidemiological research [10].

Elderly (>65years) patients with type 1diabetes were identified using appropriate codes (in the UK these are known as Read Codes). If both type 1 and type 2 read codes were present, or non-specific codes for diabetes were present, patients were defined as having type 1 diabetes if they were on insulin throughout the time they were in the practice register; not on a oral hypoglycaemic agent other than metformin at any time point; and had a diagnosis of diabetes entered before the age of 40 years.

\section{Variables}

We identified the following patient covariates that might be associated with macrovascular disease, many of which were identified based on previous studies: age, duration of diabetes, gender, smoking, presence of hypertension and glycaemic control (HbA1c) [11-16]. Outcomes of interest were ischaemic heart disease, cerebrovascular disease and peripheral vascular disease.

\section{Statistical analysis}

The prevalence of macrovascular diseases are reported as percentages. Median age, mean duration of diabetes, gender (as a percentage), smoking status (as a percentage) and mean $\mathrm{HbAlc}$ were calculated for those with and without macrovascular disease. The odds ratio (OR) and statistical significance of the association of these factors with macrovascular disease were determined by logistic regression controlling for covariates [17]. Confidence intervals for the OR are given at $95 \%(95 \% \mathrm{CI})$ and $\mathrm{P}$-values less than 0.05 were deemed significant. Data were analysed using SPSS version 19 software [18].

\section{Results}

There were 12,197 patients with type 1 diabetes identified in 2008. Among them 997 (8.2\%) were aged 65 years and above. Within this elderly population $394(39.5 \%)$ had at least one macrovascular

${ }^{*}$ Corresponding author: K. Nirantharakumar, Senior Research Fellow, Institute of Digital Healthcare, WMG, University of Warwick, Coventry, CV4 7AL, UK, E-mail: k.nirantharakumar@warwick.ac.uk

Received July 31, 2013; Accepted September 25, 2013; Published September 30, 2013

Citation: Chapman MJ, Crockett SC, Purvis TE, Anderson MJ, Whittaker PL, et al. (2013) Macrovascular Disease in the Elderly with Type 1 Diabetes. J Diabetes Metab 4: 299. doi:10.4172/2155-6156.1000299

Copyright: (c) 2013 Chapman MJ, et al. This is an open-access article distributed under the terms of the Creative Commons Attribution License, which permits unrestricted use, distribution, and reproduction in any medium, provided the original author and source are credited. 
Citation: Chapman MJ, Crockett SC, Purvis TE, Anderson MJ, Whittaker PL, et al. (2013) Macrovascular Disease in the Elderly with Type 1 Diabetes. J Diabetes Metab 4: 299. doi:10.4172/2155-6156.1000299

Page 2 of 3

complication. Ischaemic heart disease was present in $27.6 \%(\mathrm{n}=275)$, peripheral vascular disease in $14.3 \%(n=143)$ and cerebrovascular disease (stroke or transient ischaemic attack) in 9.6\% ( $\mathrm{n}=96)$. Among

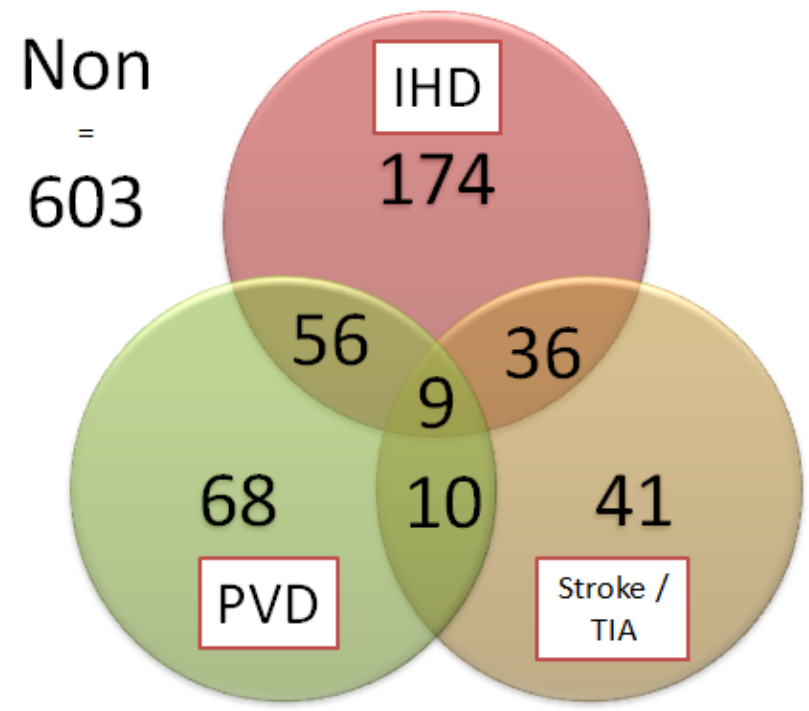

Figure 1: Distribution of macrovascular disease in elderly patients with type 1 diabetes. the 394 with macrovascular disease, $26 \%(\mathrm{n}=102)$ had 2 macrovascular diseases and 2\% ( $n=9)$ had all three (Figure 1). An overall increase in macrovascular disease was seen with an increase in age [65-69yrs: 30.86\% (125/405), 70-74yrs: 45.21\% (132/292), 75-79 yrs: $44.09 \%$ (82/186), 80-84 yrs: 47.83 (44/92), 85+ yrs: 50\% (11/22)]. Among elderly men and women with type 1 diabetes the prevalence was $41.3 \%$ and $37.2 \%$ respectively (Table 1 ).

Older age (OR 1.04; 95\%CI 1.02-1.07, $\mathrm{p}=0.001)$, longer duration of diabetes (OR 1.20; 95\%CI 1.06-1.36, $\mathrm{p}=0.003$ ), smoking (OR 1.41;95\%CI 1.06-1.87, $\mathrm{p}=0.019)$ and higher HbAlc (OR 1.16; 95\%CI 1.05-1.30, $\mathrm{p}=0.006$ ) were all shown to be significantly associated with the presence of macrovascular disease in the elderly type 1 diabetes population (Table 2). Gender did not show an association with macrovascular disease (OR for male 1.17; 95\%CI 0.89-1.54, $\mathrm{p}=0.271$ ) nor did the presence of hypertension (OR 1.26; 95\%CI 0.95-1.66, p=0.107) (Table 2). In the analysis of each macrovascular disease similar association was found with ischaemic heart disease. For peripheral vascular disease significant positive association was noted with smoking, duration of diabetes and hypertension whereas for cerebrovascular disease significant positive association was noted with age and higher HbAlc (Table 2).

\section{Discussion}

This study demonstrates a significant burden of macrovascular disease in elderly patients with Type 1 diabetes mellitus. Patients with macrovascular disease were significantly older, had a longer duration of diabetes, history of smoking and a higher HbAlc.

\begin{tabular}{|c|c|c|}
\hline Characteristics* & Patients with Macro-vascular disease & Patients without Macro-vascular disease \\
\hline Age - median in yrs. (IQR) & $72(68-77)$ & $70(67-75)$ \\
\hline Duration of diabetes-mean in yrs. (SD) & $37.7(14.9)$ & $33.6(14.0)$ \\
\hline $\begin{array}{r}\text { Gender N }(\%) \\
\text { Male } \\
\text { Female }\end{array}$ & $\begin{array}{l}229(58.1) \\
165(41.9)\end{array}$ & $\begin{array}{l}325(53.9) \\
278(46.1)\end{array}$ \\
\hline $\begin{array}{l}\text { Smoking status N (\%) } \\
\text { Never smoked } \\
\text { Smoker or Ex-smoker }\end{array}$ & $\begin{array}{l}132(33.8) \\
259(66.2)\end{array}$ & $\begin{array}{l}255(42.4) \\
346(57.6)\end{array}$ \\
\hline $\begin{array}{r}\text { Hypertension } \mathrm{N}(\%) \\
\text { Yes } \\
\text { No }\end{array}$ & $\begin{array}{l}138(35.0) \\
256(65.0)\end{array}$ & $\begin{array}{l}251(41.6) \\
352(58.4)\end{array}$ \\
\hline $\mathrm{HbA} 1 \mathrm{c}-$ mean \% (SD) & $8.3(1.4)$ & $8.10(1.2)$ \\
\hline
\end{tabular}

*SD: Standard Deviation; IQR: Inter Quartile Range

Smoking status was not recorded for 3 patients with MVD and 2 without MVD

Table 1: Characteristics of elderly patients with type 1 diabetes with and without macrovascular disease.

\begin{tabular}{|c|c|c|c|c|c|c|c|c|}
\hline Characteristics & $\begin{array}{l}\text { Adjusted odds } \\
\text { ratio for any } \\
\text { Macro-vascular } \\
\text { Disease }\end{array}$ & $\begin{array}{c}\text { P value } \\
\text { (adjusted } \\
\text { analysis) }\end{array}$ & $\begin{array}{c}\text { Adjusted odds } \\
\text { ratio for Ischaemic } \\
\text { heart Disease }\end{array}$ & $\begin{array}{c}\text { P value (adjusted } \\
\text { analysis) }\end{array}$ & $\begin{array}{l}\text { Adjusted odds } \\
\text { ratio for cerebro- } \\
\text { vascular Disease }\end{array}$ & $\begin{array}{l}\text { P value } \\
\text { (adjusted } \\
\text { analysis) }\end{array}$ & $\begin{array}{l}\text { Adjusted odds } \\
\text { ratio for peripheral } \\
\text { vascular disease }\end{array}$ & $\begin{array}{c}\text { P value (ad- } \\
\text { justed analysis) }\end{array}$ \\
\hline Age & $1.04(1.02-1.07)$ & 0.001 & $1.03(1.00-1.06)$ & 0.023 & $1.04(1.00-1.08)$ & 0.036 & $1.02(0.99-1.06)$ & 0.176 \\
\hline $\begin{array}{l}\text { Gender } \\
\text { Female }\end{array}$ & 1 & & 1 & & 1 & & 1 & \\
\hline Male & $1.17(0.89-1.54)$ & 0.271 & $0.99(0.73-1.34)$ & 0.954 & $1.51(0.94-2.42)$ & 0.086 & $1.06(0.72-1.56)$ & 0.778 \\
\hline $\begin{array}{l}\text { Smoking } \\
\text { Non smoker }\end{array}$ & 1 & & 1 & & 1 & & 1 & \\
\hline $\begin{array}{l}\text { Smoker or } \\
\text { Ex-smoker }\end{array}$ & $1.41(1.06-1.87)$ & 0.019 & $1.40(1.02-1.91)$ & 0.037 & $0.90(0.57-1.44)$ & 0.668 & $1.88(1.23-2.86)$ & 0.003 \\
\hline $\begin{array}{l}\text { Duration of } \\
\text { diabetes }\end{array}$ & $1.20(1.06-1.36)$ & 0.003 & $1.17(1.03-1.34)$ & 0.02 & $1.14(0.93-1.41)$ & 0.217 & $1.22(1.02-1.45)$ & 0.029 \\
\hline Mean $\mathrm{HbA1c}$ & $1.16(1.05-1.30)$ & 0.006 & $1.12(1.00-1.26)$ & 0.049 & $1.28(1.09-1.50)$ & 0.003 & $1.14(0.99-1.31)$ & 0.078 \\
\hline Hypertension & $1.26(0.95-1.66)$ & 0.107 & $1.20(0.88-1.63)$ & 0.243 & $1.09(0.68-1.74)$ & 0.718 & $1.79(1.18-2.71)$ & 0.006 \\
\hline
\end{tabular}

Table 2: Adjusted odds ratio for risk factors associated with the presence of macro-vascular disease in elderly patients with type 1 diabetes 
Our study has limitations. The associations with macrovascular disease do not prove causation. However, previous studies undertaken in younger diabetic and non-diabetic populations have identified blood pressure, lipids, smoking and poor glycaemic control as risk factors. Therefore our findings are in line with those from the literature [11]. The nature of the study is also affected by survival bias; those with macrovascular disease may not have survived to be included in this analysis. Therefore the prevalence may be higher than described. Formal prospective longitudinal studies would be required to provide this data. Due to the limited data made available to us, we were not able to study risk factors such as microalbuminuria and dyslipidaemia. Neither were we able to compare the prevalence over a set time period, or against a normal elderly population or elderly type 2 diabetes mellitus. Nevertheless our findings have important implications for the detection and appropriate management of macrovascular disease in the older person with type 1 diabetes.

We still lack evidence that improved control of macrovascular risk factors (lack of exercise, smoking, high blood pressure, lipids, glucose) reduces macrovascular disease in elderly patients with type 1 diabetes. The DCCT and EDIC studies which demonstrated a macrovascular protective role of good glycaemic control only recruited patients up to the age of $40 y r s$ [13]. The UKPDS (which studied patients with type 2 diabetes), similarly only recruited up to an age of 65 [19]. Therefore evidence that the approaches utilised for younger patients with macrovascular disease will work in an older patients is still required.

We conclude elderly patients with type 1 diabetes have a high burden of macrovascular disease. We propose there is a need to: 1) promote early detection and appropriate management of macrovascular disease; 2) determine whether the approaches to reducing macrovascular risk validated in younger patients with type 1 diabetes also applies to older patients; and 3) implement these validated approaches to reducing macrovascular risk.

\section{References}

1. Department of Health (2010) Diabetes -Six years on: delivering the Diabetes National Service Framework.

2. Mustonen J, Uusitupa M, Mäntysaari M, Länsimies E, Pyörälä K, et al. (1997) Changes in autonomic nervous function during the 4-year follow-up in middleaged diabetic and nondiabetic subjects initially free of coronary heart disease. $\mathrm{J}$ Intern Med 241: 227-235
3. Kuller LH, Velentgas P, Barzilay J, Beauchamp NJ, O'Leary DH, et al. (2000) Diabetes mellitus: subclinical cardiovascular disease and risk of incident cardiovascular disease and all-cause mortality. Arterioscler Thromb Vasc Biol 20: 823-829.

4. Syed A, Hussain S, Nightingale P, De P, Charlton MH, et al. (2007) Cardiovascular risk factors and their management in 1282 adult people with type 1 diabetes. Curr Med Res Opin 23: 2921-2927.

5. Borch-Johnsen K (1999) Improving prognosis of type 1 diabetes. Mortality, accidents, and impact on insurance. Diabetes Care 22 Suppl 2: B1-3.

6. Miller RG, SecrestAM, Sharma RK, Songer TJ, Orchard TJ (2012) Improvements in the life expectancy of type 1 diabetes: the Pittsburgh Epidemiology of Diabetes Complications study cohort. Diabetes 61: 2987-2992.

7. (2006) CSD Medical Research, UK.

8. The Health Improvement Network.

9. (2010) THIN Database Description.

10. Lewis JD, Schinnar R, Bilker WB, Wang X, Strom BL (2007) Validation studies of the health improvement network (THIN) database for pharmacoepidemiology research. Pharmacoepidemiol Drug Saf 16: 393-401.

11. Lewis S, MacLeod M, McKnight J, Morris A, Peden N, et al. (2005) Predicting vascular risk in Type 1 diabetes: stratification in a hospital based population in Scotland. Diabet Med 22: 164-171.

12. Morrish NJ, Stevens LK, Fuller JH, Jarrett RJ, Keen H (1991) Risk factors for macrovascular disease in diabetes mellitus: the London follow-up to the WHO Multinational Study of Vascular Disease in Diabetics. Diabetologia 34: 590-594.

13. Nathan DM, Cleary PA, Backlund JY, Genuth SM, Lachin JM, et al. (2005) Intensive diabetes treatment and cardiovascular disease in patients with type 1 diabetes. N Engl J Med 353: 2643-2653.

14. Laing SP, Swerdlow AJ, Slater SD, Burden AC, Morris A, et al. (2003) Mortality from heart disease in a cohort of 23,000 patients with insulin-treated diabetes. Diabetologia 46: 760-765.

15. Laing SP, Swerdlow AJ, Carpenter LM, Slater SD, Burden AC, et al. (2003) Mortality from cerebrovascular disease in a cohort of 23000 patients with insulin-treated diabetes. Stroke 34: 418-421.

16. Schluter M, Reimers B, Castriota F, Tubler T, Cernetti C, et al. (2007) Impact of diabetes, patient age, and gender on the 30-day incidence of stroke and death in patients undergoing carotid artery stenting with embolus protection: a post-hoc subanalysis of a prospective multicenter registry. J Endovasc Ther 14: $271-278$.

17. Xing G, Xing C (2010) Adjusting for covariates in logistic regression models Genet Epidemiol 34: 769-771.

18. IBM Corp (2011) SPSS Statistics.

19. UK Prospective Diabetes Study Group (1998) Tight blood pressure control and risk of macrovascular and microvascular complications in type 2 diabetes: UKPDS 38. UK Prospective Diabetes Study Group. BMJ 317: 703-713. 